\title{
Live Sculpture
}

\author{
Chiara Passa \\ Rome, Italy \\ http://www.chiarapassa.it \\ chiarapassa@gmail.com
}

\section{INTRODUCTION}

"Live sculpture" is an interactive and performativity video-sculpture built as a communicating mirror where the body of the viewer is fully participating.

\section{LIVE SCULPTURE}

When the audience is in front of the "Live sculpture" mirror is scanned and filmed in real time by a webcam installed behind the frame, then revived and reshaped in a human scale video projection, as a three-dimensional marble sculpture.

This new three-dimensional live image of the viewer-sculpture is entirely built of an everchanging interactive mesh, tuning into and reacting to body movement, environment light and speed of the spectator's movement.

My artistic research has always analysed changes in 'liquid space' throughout a variety of techniques, technologies and devices.

The 'liquid space' in "Live sculpture" unfolds by the protagonists themselves aiming to reshape the human being condition, transforming it into something alive and vibrant, challenging the notion of sculpture itself.

The mirror is a sort of "mirror-mirror on the wall", but instead to make appear the 'fairest of them all', it creates from the viewers, distorted threedimensional monsters of themselves bringing out the hidden and chilling part of the psyche. The experience of watching themselves in another atmosphere begins a voyage where synthetic shapes become design, structure, figure and illusoriness.

A sensitive, unsolved, mental and transitory vision of the body is adjusted to the hidden requirements of the explorer (audience). The artwork is closely linked to the aesthetic and to the tensions of the new technologies exalting the conjunction between what is visceral, voluptuous and mind-expanding.
If the space is the extension in all the directions, by our intuitions, of the real world in which material bodies are placed, "Live sculpture" wants to expand these possibilities of perception.

"Live sculpture" is also a software-artwork (osx App) that can be considered a unique piece. Although it is digital and reproducible, it appears different every time thanks to the spectator's everchanging subjectivity. "Live sculpture" restores the aura of digital artwork and solves the issue related to the multiple in art. It's a multiple but always a different one.

\subsection{How I have designed "Live sculpture"}

I have built "Live sculpture" using the free developer tools Quartz Composer and Xcode. In Quartz Composer I have set up the workflow scenario using a video input (a webcam) device connected to several patches performing many functions - eventually rendering in mesh. I have not used any prefab app in QC. Then, I have constructed the software (osx-app standalone) within Xcode using the Cocoa and the Quartz Composer frameworks that are able to import and rework the Quartz Composer files.

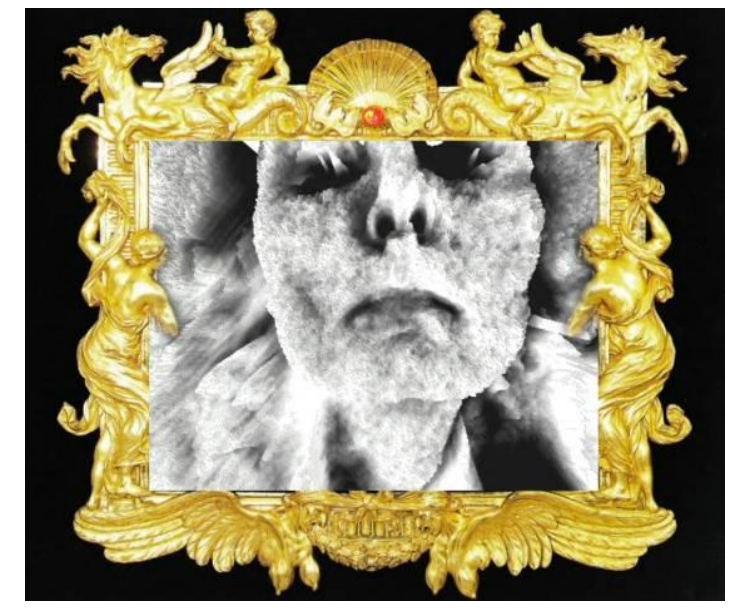

Figure 1: "Live sculpture" 


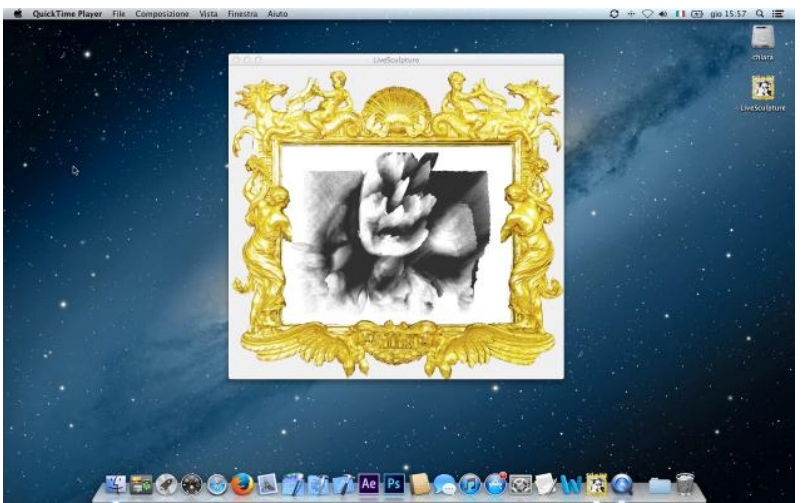

Figure 2: screenshot from "Live sculpture" osx-app

\subsection{How I had the idea of "Live sculpture"}

In 2009, I created "The virtual Prigione", which I launched on January 2010 as a net-artwork performing an interactive portrait - of me - a web based video-sculpture inspired by the concept of the latest "unfinished" sculptures of Michelangelo, so named "Prigioni."

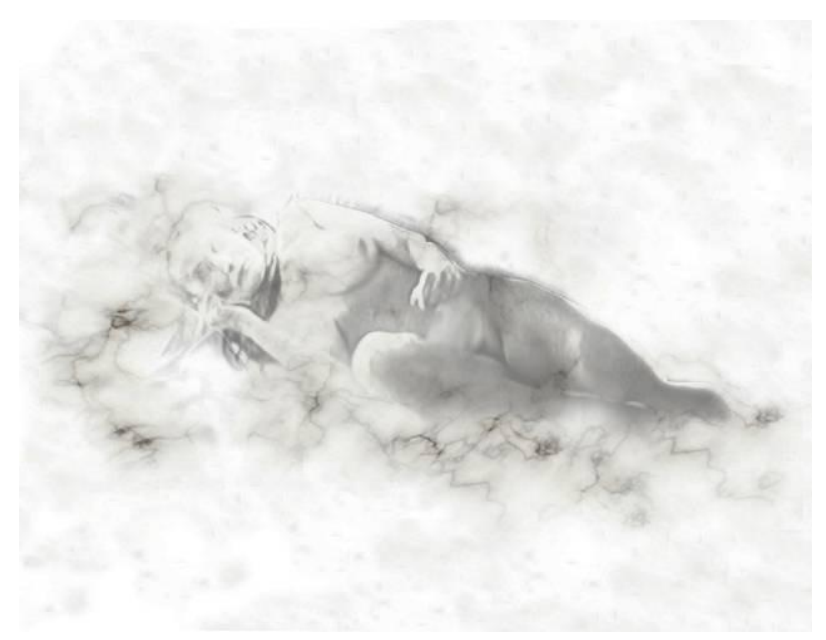

Figure 3: "The Virtual Prigione", net-artwork

Then, I created an IOS-App version of the netartwork project where the virtual statue - a sort of cyber human figure - is totally dynamic and interactive; changing diverse poses, it can be sculpt just using the finger as a chisel. In both the versions (IOS-App and web based artwork), "The virtual Prigione" represents various states of being. The spectator can choose to liberate the sculpture from the marble and its dependence material - so, the body-statue sublimates and the marble becomes virtual idea. Or, the user can also pick the option to imprison the statue into the marble, bringing it to the primordial state where the mass has a simple/essential geometric figure.

"Live sculpture" was exhibited at:

- XIII Festival Internacional de la Imagen, Manizales, 2013.

- $\quad$ FILE | Electronic Language International Festival, São Paulo, 2011.

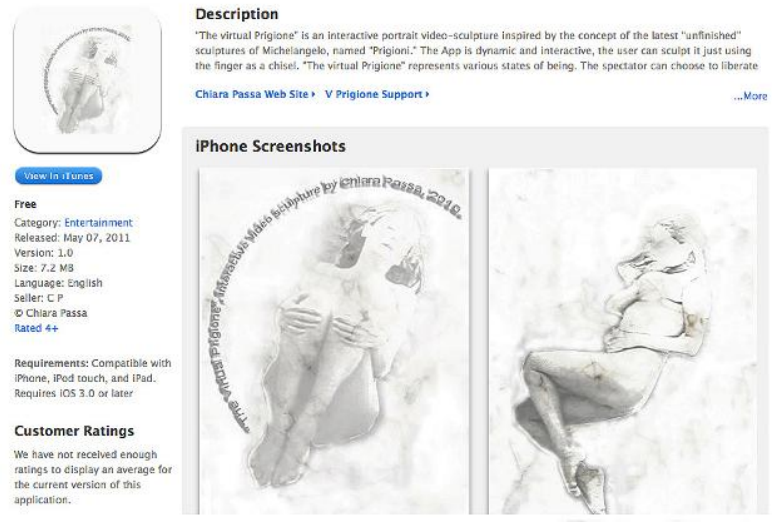

Figure 4: "The Virtual Prigione", IOS-App

\section{REFERENCES}

Online sources (retrieved 13 June 2015):

Net-artwork

http://www.chiarapassa.it/videoenglish.html

Concept

http://www.chiarapassa.it/videography.html

Images

http://www.chiarapassa.it/livesculptureimages.htm

App

http://www.chiarapassa.it/virtualprigioneapp.html

Video-demo 2

https://www.youtube.com/watch?v=HX5aDG9Wn I 